\title{
Understanding the complexities of bake hardening
}

\author{
S. Das ${ }^{1,2}$, S. B. Singh ${ }^{2}$, O. N. Mohanty ${ }^{3}$ and H. K. D. H. Bhadeshia*1
}

\begin{abstract}
The basic science behind bake hardening steels is well understood in terms of the interactions between interstitial solutes and dislocations. However, the manufacture of such alloys involves a variety of other variables, the interactions between which are influential in controlling the extent of hardening. In the present work, a model which includes the chemical composition of the steel, the strain before aging and the annealing and aging conditions is developed and used to explore certain anomalies in the published literature. It is found that whereas the roles of deformation and aging can be rationalised, the generic effect of niobium is associated with large uncertainties and warrants further experimental work.
\end{abstract}

Keywords: Bake hardening, Strain aging, Dislocations, Automobiles

\section{Introduction}

Bake hardening steels consist mainly of ferrite containing a minute concentration of carbon $(<25 \mathrm{ppm})$ in solid solution. They are used in the manufacture of automobile bodies which after forming into shape are painted. When the paint is baked in the temperature range of $150-200^{\circ} \mathrm{C}$, the dissolved carbon migrates to pin any free dislocations introduced during the forming operation (Fig. 1). The resultant bake hardening response $\Delta \sigma$ is a useful design feature of the steel. There has been an excellent recent review on the subject. ${ }^{1}$

The metallurgical principles of bake hardening are simple to understand, but its quantitative expression depends on the detailed chemical composition, deformation and heat treatment parameters. As a consequence, mathematical models of bake hardening steels tend not to deal with the most general cases but rather, subsets of the overall problem. ${ }^{3,4}$

There are a number of inconsistent issues reported in the literature. It has been reported for example that $\Delta \sigma$ decreases monotonically with $\varepsilon^{2,5}$ although other investigations suggest that the bake hardening response is insensitive to the prestrain. ${ }^{6,7}$

The purpose here was to create a model using neural networks, which is inclusive of all the variables described above.

\section{Method}

A general method for treating complex data is the neural network in a Bayesian framework. This has been documented thoroughly ${ }^{8-13}$ and applied extensively in

\footnotetext{
${ }^{1}$ Materials Science and Metallurgy, University of Cambridge, Cambridge CB2 3QZ, UK

${ }^{2}$ Metallurgical and Materials Engineering, Indian Institute of Technology, Kharagpur, India

${ }^{3}$ Biju Patnaik University of Technology, Orissa, India

*Corresponding author, email hkdb@cam.ac.uk
}

the study and design of steels. ${ }^{14-24}$ For this reason only specific points of relevance are introduced here.

The network is essentially a non-linear regression method which, because of its flexibility, is able to capture intricate patterns within the data. As such, the network is described by an equation combined with coefficients, analogous to the coefficients and equation describing linear regression. There are techniques implemented which avoid overfitting, and which minimise the danger of modelling noise rather than the underlying trends. There are a number of interesting outputs other than the coefficients which help in understanding the nature of the network and the data used to create the model. First, there is the noise in the output, associated with the fact that a different result may be obtained from identical experiments, because some unknown variable which influences the output is not controlled. Second, there is the uncertainty of modelling: many mathematical functions may adequately represent known data and yet behave differently when extrapolated. A knowledge of this uncertainty is particularly helpful in interpreting the trends when models are extrapolated, and in indicating the extent to which extrapolation may be exploited in practice.

\section{Data}

The data (Table 1) were compiled mostly from the published literature ${ }^{1,2,6,7,25-28}$ together with some unpublished research. ${ }^{29}$ Some publications did not state the concentrations of $\mathrm{Ti}, \mathrm{Nb}, \mathrm{Al}$ and $\mathrm{Si}$, in which case they were assumed to be zero since these usually are all deliberate additions. Similarly, the temperature of deformation before baking was assumed to be $25^{\circ} \mathrm{C}$ when not stated. The cooling rate from the annealing temperature, grain size and the strain rate should influence bake hardening, but were omitted as variables given the lack of data - this should contribute to the noise in the output. 


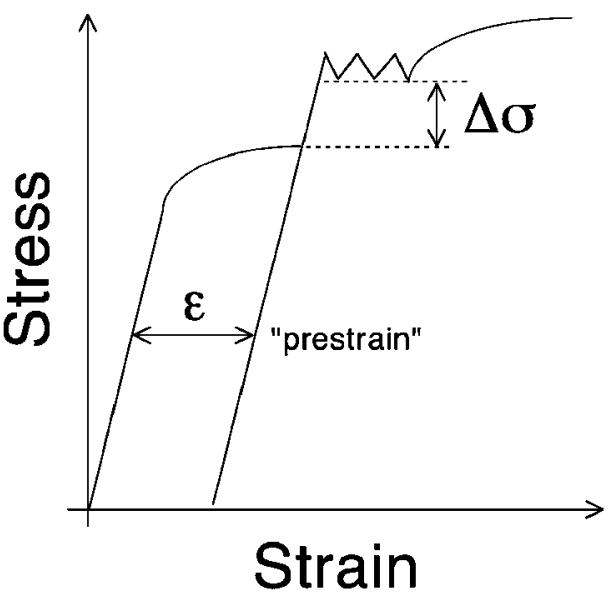

1 Definition of bake hardening $(\Delta \sigma)$ which is conducted on samples deformed to plastic strain $\varepsilon$, often referred to as 'prestrain"2

It is worth emphasising that the ranges of each of the variables stated in Table 1 do not define the limits beyond which extrapolation is considered to occur. This is because the data are not necessarily uniformly distributed in the variable space. The modelling uncertainty, on the other hand, is an excellent indicator of positions in the input space where knowledge is sparse.

The extent of agreement between calculated and measured values of bake hardening, bearing in mind that procedures have been implemented to avoid overfitting, ${ }^{8,9,11}$ is illustrated in Fig. 2. The plot represents the entire available dataset of some 621 experiments, with the calculations done using the optimised committee of models as described elsewhere. ${ }^{8,9,11}$ The error bars represent $\pm 1 \sigma$ modelling uncertainty.

\section{Application of model}

Three different steels were selected in order to explore the behaviour of the model, both with respect to known and understood trends and in order to resolve some inconsistencies across published data. The parameters representing these steels are listed in Table 2. Steel 3 is interesting because its deformation temperature is greater than that at which it was bake hardened. The three alloys also cover a significant range of prestrain $(\varepsilon)$. Steel 1 has a particularly high manganese concentration

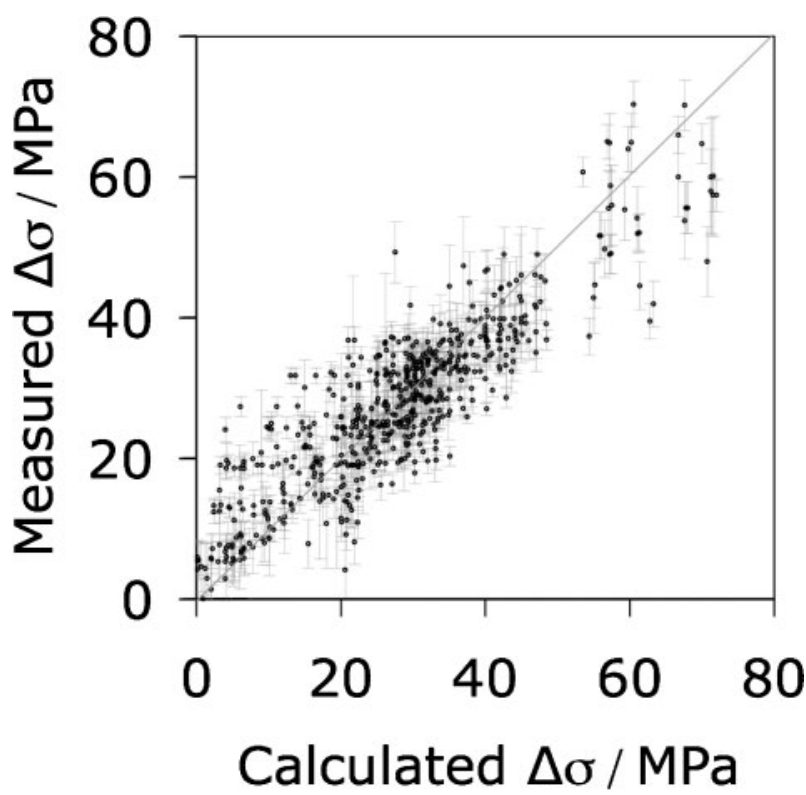

2 Performance of model: modelling uncertainty illustrated corresponds to \pm 1 standard deviation

and there are detailed differences in the microalloying additions.

The data listed in Table 2 form the basis for studying trends. It may henceforth be assumed that when a plot of $\Delta \sigma$ is presented against a particular variable (such as

Table 2 Examples of steels studied using model

\begin{tabular}{lccc}
\hline Variable & Steel 1 & Steel 2 & Steel 3 \\
\hline C, wt-\% & 0.0021 & 0.002 & 0.0023 \\
Mn, wt-\% & 0.53 & 0.09 & 0.16 \\
S, wt-\% & 0.012 & 0.003 & 0.023 \\
Si, wt-\% & 0.001 & 0.000 & 0.000 \\
P, wt-\% & 0.029 & 0.045 & 0.011 \\
N, wt-\% & 0.002 & 0.0016 & 0.0032 \\
Nb, wt-\% & 0.006 & 0.000 & 0.005 \\
Ti, wt-\% & 0.008 & 0.007 & 0.06 \\
Al, wt-\% & 0.047 & 0.049 & 0 \\
Annealing temperature, ${ }^{\circ} \mathrm{C}$ & 820 & 850 & 900 \\
Annealing time, s & 80 & 60 & 60 \\
Prestrain, \% & 1 & 2 & 4 \\
Prestrain temperature, ${ }^{\circ} \mathrm{C}$ & 25 & 25 & 200 \\
Aging temperature, ${ }^{\circ} \mathrm{C}$ & 100 & 50 & 170 \\
Aging time, min & 98.9 & 283.7 & 20 \\
\hline
\end{tabular}

Table 1 Properties of data used in creating model

\begin{tabular}{|c|c|c|c|c|}
\hline Variables & Minimum & Maximum & Average & Standard deviation \\
\hline C, wt-\% & 0.002 & 0.03 & 0.0093 & 0.0122 \\
\hline Mn, wt-\% & 0.09 & 0.53 & $0 \cdot 1665$ & $0 \cdot 1192$ \\
\hline S, wt-\% & 0.003 & 0.023 & 0.0061 & 0.0056 \\
\hline Si, wt-\% & 0 & 0.022 & 0.0044 & 0.0072 \\
\hline$P, w t-\%$ & 0.007 & 0.045 & 0.0312 & 0.0173 \\
\hline N, wt-\% & 0.0016 & 0.0034 & 0.0021 & 0.0007 \\
\hline $\mathrm{Nb}, \mathrm{wt}-\%$ & 0 & 0.018 & 0.001 & 0.0027 \\
\hline Ti, wt-\% & 0 & 0.06 & 0.0095 & 0.015 \\
\hline $\mathrm{Al}, \mathrm{wt}-\%$ & 0 & 0.05 & 0.0448 & 0.014 \\
\hline Annealing temperature, ${ }^{\circ} \mathrm{C}$ & 720 & 900 & $857 \cdot 7$ & $20 \cdot 2$ \\
\hline Annealing time, $s$ & 1 & 250 & 98 & $75 \cdot 9$ \\
\hline Prestrain, \% & 1 & 10 & 4 & $2 \cdot 5$ \\
\hline Prestrain temperature, ${ }^{\circ} \mathrm{C}$ & 25 & 250 & 33 & $35 \cdot 5$ \\
\hline Baking temperature, ${ }^{\circ} \mathrm{C}$ & 25 & 250 & $112 \cdot 5$ & 50 \\
\hline Baking time, $\min$ & $0 \cdot 1$ & 49803 & 1346 & $5046 \cdot 7$ \\
\hline Bake hardening, MPa & $0 \cdot 1$ & 72 & $27 \cdot 92$ & $14 \cdot 14$ \\
\hline
\end{tabular}



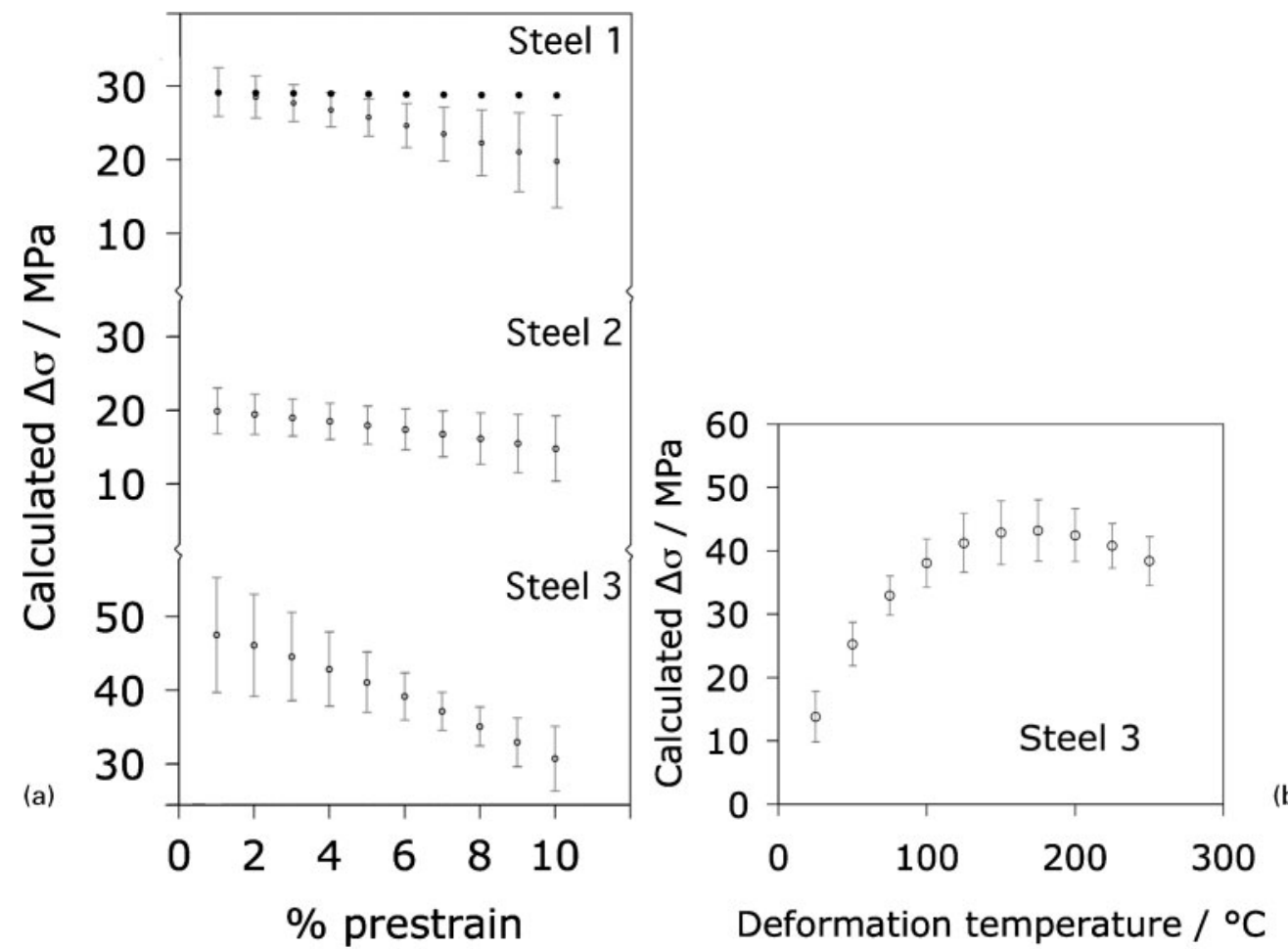

3 a influence of prior deformation on tendency for bake hardening (values of other parameters used in calculations are given in Table 2, with exception of filled points of steel 1, where aging time is set at $8000 \mathrm{~min}$ ) and $b$ calculations for steel $3, \varepsilon=4 \%$ as function of deformation temperature

$\mathrm{Mn})$, then the values of all the other variables correspond to those listed in Table 2 .

\section{Deformation and aging}

The prestrain refers to the plastic deformation before the aging treatment; in laboratory experiments such as those considered here, it is applied homogeneously, although in practice the state of deformation will depend on the application and shape of the component.

It was pointed out earlier that $\Delta \sigma$ decreases monotonically with $\varepsilon,{ }^{2,5}$ although others suggest the $\Delta \sigma$ should be insensitive to the prestrain. 6,7

For the conditions listed in Table 2, steels 1-3 have $\varepsilon=1,2,4 \%$ respectively, and all show a reduction in $\Delta \sigma$ as a function of $\varepsilon$, as illustrated in Fig. $3 a$. Such a reduction might be expected if not all of the dislocations introduced by deformation become pinned during the aging period. A larger $\varepsilon$ would leave more free dislocations and hence a diminished bake hardening response. However, this hypothesis would only be valid if the aging conditions are insufficient to ensure the pinning of all available dislocations.

In their analysis, De et al. ${ }^{7}$ showed that the maximum increase in yield strength corresponding to the completion of carbon atmosphere formation on dislocations was independent of the level of prestrain. This has been simulated here for steel 1 by increasing the aging time to $8000 \mathrm{~min}$; the results are illustrated in Fig. $3 a$ and confirm that the strength increment becomes insensitive to the prestrain when the aging time is long.

It follows therefore that $\Delta \sigma$ will only decrease as a function of $\varepsilon$ when the aging conditions do not allow sufficient time for the dislocation-pinning process to be completed. This is entirely consistent with the classical work on strain aging by Cottrell and Bilby, also involving steels with dissolved carbon concentrations $<0.003$ wt $-\%{ }^{30}$

An interesting observation in Fig. $3 a$ is that steel 3 has a very high strain hardening response at low $\varepsilon$, and hence $\Delta \sigma$ exhibits a larger decline as the prestrain increases. This is because the alloy was deformed at $200^{\circ} \mathrm{C}$ which is greater than the aging temperature of $170^{\circ} \mathrm{C}$ (Table 2). Dynamic strain aging is therefore likely at the deformation temperature. ${ }^{31}$ This is also proven by the calculations presented in Fig. $3 b$, where it is seen that a reduction in the deformation temperature to values less than the aging temperature leads to a dramatic decline in $\Delta \sigma$.

The effect of temperature and time on strain aging has long been understood. ${ }^{30}$ Figure $4 a$ shows the calculated dependence of $\Delta \sigma$ on the aging temperature. Also plotted is the normalised measure of strain aging, $H=$ $\left(H_{\mathrm{t}}-H_{0}\right) /\left(H_{\mathrm{M}}-H_{0}\right)$ versus $D t$ where for a given steel, $H_{\mathrm{t}}, H_{0}$ and $H_{\mathrm{M}}$ are the instantaneous, minimum and maximum values respectively of $\Delta \sigma . \quad D=5 \cdot 2 \times$ $10^{-4} \exp \{-9000 / T\} \mathrm{cm}^{2} \mathrm{~s}^{-1}$ is the diffusion coefficient for carbon in ferrite ${ }^{30}$ and $t$ is the aging time. The calculated data from the three different steels are rationalised in this way (Fig. $4 b$ ). It is interesting that the major part of the strain aging is completed at low values of $D t<2 \times 10^{-9} \mathrm{~cm}^{2}$. This is consistent with the substantial bake hardening apparent even from room temperature aging (Fig. 4).

\section{Other parameters}

Calculations indicated that for all steels, $\Delta \sigma$ increased with the annealing temperature. However, the trends were all associated with large modelling uncertainties and are not therefore reproduced here. The trends may nevertheless be correct given that the solubility of carbon in ferrite increases with the annealing 

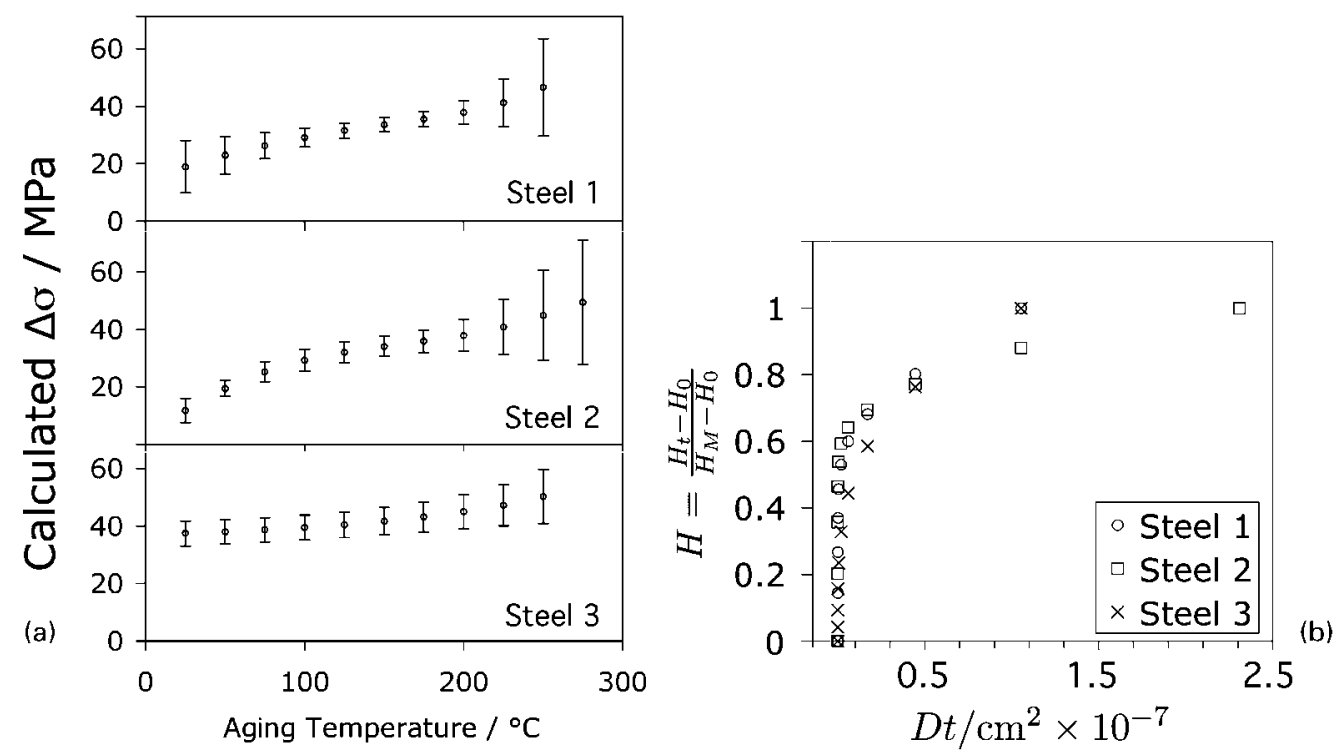

4 a influence of aging temperature on tendency for bake hardening (values of other parameters used in calculations are given in Table 2) and $b$ interpretation of data (units of time are seconds)

temperature, as verified using MTDATA. $^{32}$ The influence of niobium additions on the bake hardening tendency was too uncertain to be reliably perceived on the basis of the data used to create the model (Fig. 5a). From a metallurgical point of view, both niobium and titanium are expected to reduce the bake hardening response because they are strong carbide formers. A meaningful trend is indeed observed in the case of titanium for calculations made on steel 2 (Fig. 5b).

Manganese in solution is known to associate with carbon atoms also in solution, thereby limiting the ability of the latter to participate in bake hardening. ${ }^{33,34}$ This effect is captured by the neural network model as illustrated in Fig. $5 c$.

In future experimental work, it would be useful to report the cooling rate from the annealing temperature. Although the equilibrium concentration of carbon in solution can be estimated as a function of temperature using phase diagram calculations, the concentration may deviate from equilibrium if the rate is sufficiently large. The authors' attempts at correlating the amount of dissolved carbon calculated for the annealing temperature, against the bake hardening response proved unsuccessful, presumably because of the absence of information on cooling rates.

\section{Comparison with alternate model}

Dehghani and Shafiei ${ }^{35}$ have just published a neural network model of bake hardening; it is appropriate therefore to compare the present outcomes with their work. Judging from their Fig. 5, the analysis is based on a total of 18 experimental data from three different steels, and includes the total carbon concentration, prestrain, initial yield strength and aging temperature as variables. The data were generated from tensile tests for prestrains of 2, 4, 6 and $8 \%$ at room temperature, and aging temperatures of $100,150,200$ and $250^{\circ} \mathrm{C}$ for $20 \mathrm{~min}$.

The analysis is obviously based on limited data and a conservative set of inputs compared with the work reported here (621 experiments, 15 inputs). But more significantly, Dehghani and Shafiei do not report any quantitative assessment of errors and modelling uncertainties. This is a shortcoming which makes it impossible to assess the significance of their results.

In their Fig. 3, Dehghani and Shafei show measurements which indicate that bake hardening increases with prestrain. This contradicts the opposite trends illustrated in Fig. 3. It is believed that their experimental trends (illustrated as curves rather than points) are presented in a misleading manner given the limited number of experiments they conducted, it is inevitable that other variables such as the annealing temperature are not kept constant in generating these plots. The paper unfortunately does not contain the necessary information or detail to comment further on their observations, or to reproduce their work or indeed to simulate their results using the present model.

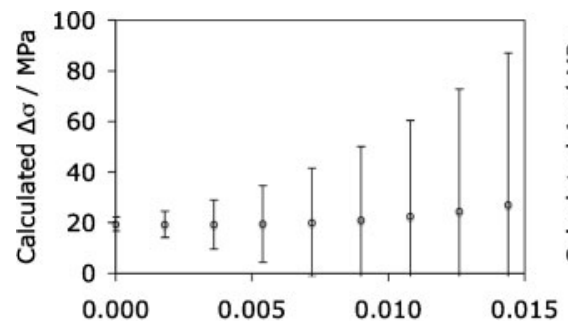

(a)

$\mathrm{Nb} / \mathrm{wt} \%$

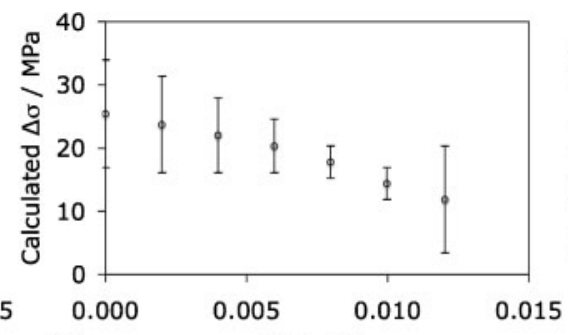

(b)

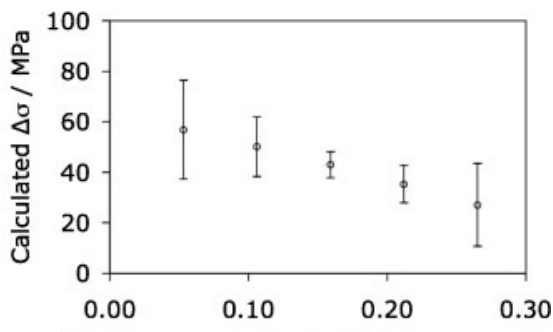

(c) $\quad \mathrm{Mn} / \mathrm{wt} \%$

5 Calculated effect of $a \mathrm{Nb}$ (uncertainties are too large to perceive significant trend), $b \mathrm{Ti}$ and $c \mathrm{Mn}$ of steel 2 


\section{Summary}

It is evident from this analysis that although there is a great deal understood about bake hardening steels, there are significant gaps in knowledge when the whole set of variables is considered together. With the neural network model it has been possible to rationalise the effects of the 'prestrain' and aging temperature on the extent of bake hardening. A number of other trends, such as the influence of the solutes $\mathrm{Mn}$ and Ti are well defined. However, it has not been possible to extract a comprehensive understanding of the effects of all the variables, for example niobium, because the range of data available has been shown to be inadequate for analysis purposes.

The software developed is available freely from www.msm.cam.ac.uk/map/mapmain.html

\section{Acknowledgement}

S. Das is grateful to the Commonwealth Scholarships Commission (UK) for financial support towards his studies in Cambridge University during 2006-2007.

\section{References}

1. L. J. Baker, S. R. Daniel and J. D. Parker: Mater. Sci. Technol., 2002, 18, 355-367.

2. P. Elsen and H. P. Hougardy: Steel Res., 1993, 64, 431-436.

3. B. Soenen, A. K. De, S. Vandeputte and B. C. D. Cooman: Acta Mater., 2004, 52, 3483-3492.

4. S. Berbenni, V. Favier, X. Lemoine and M. Berveiller: Scr. Mater., 2004, 51, 303-308.

5. A. van Snick, K. Lips, S. Vandeputte, B. C. D. Cooman and J. Dilewijns: in 'Modern low carbon and ultra low-carbon sheet steels for cold forming: processing and properties', (ed. W. Bleck), Vol. 2, 413; 1998, Aachen, Verlag Mainz.

6. A. K. De, S. Vandeputte and B. C. D. Cooman: Scr. Mater., 1999, 41, 831-837.

7. A. K. De, K. D. Blauwe, S. Vandeputte and B. C. D. Cooman: J. Alloys Compd., 2000, 310, 405-410.

8. D. J. C. MacKay: Neur. Comput., 1992, 4, 448-472.

9. D. J. C. MacKay: Neur. Comput., 1992, 4, 415-447.
10. B. G. Sumpter and D. W. Noid: Ann. Rev. Mater. Sci., 1996, 26, 223-277.

11. H. K. D. H. Bhadeshia: ISIJ Int., 1999, 39, 966-979.

12. D. J. C. MacKay: 'Information theory, inference, and learning algorithms'; 2003, Cambridge, Cambridge University Press.

13. Z. Sterjovski, D. Nolan, K. Carpenter, D. Dunne and J. Norrish: J. Mater. Process. Technol., 2005, 170, 536-544.

14. H. K. D. H. Bhadeshia, D. J. C. MacKay and L.-E. Svensson: Mater. Sci. Techno., 1995, 11, 1046-1051.

15. T. Goswami: ISIJ Int., 1996, 36, 354-360.

16. S. B. Singh and H. K. D. H. Bhadeshia: Mater. Sci. Eng. A, 1998, A245, 72-79.

17. J. M. Vitek, Y. S. Iskander and E. M. Oblow: Weld. J., Res. Suppl., 2000, 79, 33s-50s.

18. J. Tenner, D. A. Linken, P. F. Morris and T. J. Bailey: Ironmaking Steelmaking, 2001, 28, 15-22.

19. D. Dunne, H. Tsuei and Z. Sterjovski: ISIJ Int., 2004, 44, 15991607.

20. Z. Guo and W. Sha: Comput. Mater. Sci., 2004, 29, 12-28.

21. R. Kemp, G. A. Cottrell, H. K. D. H. Bhadeshia, G. R. Odette, T. Yamamoto and H. Kishimoto: J. Nucl. Mater., 2006, 348, 311328.

22. S. Chatterjee, M. Murugananth and H. K. D. H. Bhadeshia: Mater. Sci. Technol., 2007, 23, 819-827.

23. H. K. D. H. Bhadeshia: ISIJ Int., 2001, 41, 621-640.

24. H. S. Wang, J. R. Yang and H. K. D. H. Bhadeshia: Mater. Sci. Technol., 2005, 21, 1323-1328.

25. K. Dehghani and J. J. Jonas: Metall. Mater. Trans. A, 2000, 31A, 1375-1384.

26. W. Al-Shalfan: 'Bake hardening of microalloyed ULC steels', $\mathrm{PhD}$ thesis, Colorado School of Mines: Golden, Colorado, USA, 2001.

27. J. Z. Zhao, C. Mesplont and B. C. de Cooman: ISIJ Int., 2001, 41, $492-497$.

28. M. de Meyer, K. D. Wit and B. C. de Cooman: Steel Res., 2000, 71, $511-518$.

29. S. Das: 'Bake hardening steels', Unpublished work.

30. A. H. Cottrell and B. A. Bilby: Proc. Phys. Soc. A, 1949, 62A, 49 62.

31. N. Tsuchida, E. Baba, K. Nagai and Y. Tomota: Acta Mater., 2005, 53, 265-270

32. NPL: 'MTDATA: software', National Physical Laboratory, Teddington, UK, 2006.

33. C. C. Li and W. C. Leslie: Metall. Trans. A, 1978, 9A, 1765 1775 .

34. S. Gündüz: Ironmaking Steelmaking, 2002, 29, 341-346.

35. K. Dehghani and A. Shafiei: Mater. Lett., doi: 10.1016/ J.matlet.2007.04.114. 